\section{Diabetic complications in childhood}

Childhood diabetes is beset with many problems but fortunately those associated with long-term microangiopathic complications are rare. Serious lesions in the eyes, kidneys, and nerves are not usually seen by paediatricians, though the appearance of these complications in teenagers is much more common than is generally supposed.

Diabetic retinopathy has not been seen before 10 years of age, ${ }^{1}$ but is found in $4 \%-12 \%$ of diabetics in their teens. ${ }^{1-3}$ More recently a study using retinal photography found signs of retinopathy in $14 \%$ of 154 diabetic children attending camps. ${ }^{4}$ When the same 154 children were examined by fluorescein angiography three-quarters appeared to be affected, often after only a few years of diabetes. The interpretation of these findings is uncertain in the absence of control information and of any knowledge of the long-term natural history of lesions seen on fluorescein angiography. Such a high prevalence of retinopathy must, however, give grounds for concern when added to the knowledge that $4 \%$ of those registered blind in England and Wales aged 15-29 years are diabetics ${ }^{5}$ and that 30 years after the onset of their disease up to $90 \%$ of diabetics have retinopathy with or without other complications. ${ }^{3}$

There are other indications that microangiopathy is already established in childhood. Proteinuria due to diabetic glomerulosclerosis is already found in $3 \%-4 \%$ of children. ${ }^{1-3}$ Though it is less common than retinopathy, this rate is alarming enough -renal failure is responsible for as many as half of all deaths of diabetic children. ${ }^{6}$ Diffuse glomerulosclerosis has been seen in biopsy specimens from teenage diabetics, ${ }^{7}$ and mesangial and basement membrane thickening has been reported in a child of 9 years. ${ }^{8}$ Muscle biopsy specimens have shown basement membrane thickening in teenagers, ${ }^{9}$ and another small vessel defect which has been recorded is conjunctival venular dilatation. ${ }^{10}$ Neuropathy in children is rare, though peripheral nerve conduction is found to be reduced in diabetics compared with non-diabetic children. ${ }^{11} 12$

Studies of diabetic complications always include a group of patients who have been spared all these long-term sequelae. One-quarter of the children examined by fluorescein angiography had no retinal changes, ${ }^{4}$ while later in life some diabetics are still free from all complications after over 40 years. ${ }^{13}$ The reason for this is not understood. Is there a type of diabetic less susceptible to vascular abnormalities? Heredity may play a part. In identical twins suffering from diabetes both members of the pair have almost identical retinal appearances, being either both normal or both showing the same degree of retinopathy. ${ }^{14}$ There are also some rare families with dominantly inherited maturity-onset diabetes in young people whose long-term complications are both infrequent and mild. ${ }^{15}$ The suggestion that prevalence of retinopathy is related to HLA types ${ }^{16}$ needs to be confirmed.

We are still ignorant of the causes of these microvascular complications; and once established they are permanent, if not necessarily progressive. In the care of diabetics good metabolic control is still the only tool physicians can use to try to prevent or slow the progression of these abnormalities. ${ }^{1718}$ Good control should be established as early as possible in childhood diabetes: to do this, twice-daily insulin injections are needed (at least from puberty), and sensible but not "free" diets should be prescribed. Advice needs to be available to the families at all times, and the specialist health visitor has a most important part to play. Monitoring of the blood glucose concentration at home may also be of immense value in many cases and improve standards of control. Above all, close collaboration between paediatricians and diabetic physicians is needed to ensure uniformity of treatment and to smooth the transition from paediatric to adult clinics.

1 Sterky, G, Acta Paediatrica, 1963, suppl 144, 5.

2 Pond, H, in Clinical Diabetes and Its Biochemical Basis, eds W G Oakley, D A Pyke, and K W Taylor, p 590. Oxford, Blackwell, 1968.

${ }^{3}$ White, P, and Graham, C A, in Foslin's Diabetes Mellitus, eds A Marble, P White, R F Bradley, and L P Krall, p 339. Philadelphia, Lea and Febiger, 1971

${ }^{4}$ Malone, J I, van Cader, T C, and Edwards, W C, Diabetes, 1977, 26, 673.

Sorsby, A, Incidence and Causes of Blindness in England and Wales. London, HMSO, 1966.

${ }^{6}$ Marks, H H, American fournal of Public Health, 1965, 55, 416.

7 Thomsen, A C, The Kidney in Diabetes Mellitus. Copenhagen, Munksgaard, 1965.

${ }^{8}$ Balodimos, M C, Legg, M A, and Bradley, R F, Diabetes, 1971, 20, 622.

${ }^{9}$ Ratzan, S K, et al, Diabetes, 1977, 26, suppl 1, 370.

${ }^{10}$ Ditzel, J, Beaven, D W, and Renold, A E, Metabolism, 1960, 9, 400.

11 Eeg-Olofsson, O, and Petersen, I, Acta Paediatrica Scandinavica, 1966, $55,163$.

12 Gamstorp, I, et al, Diabetes, 1966, 15, 411.

${ }^{13}$ Oakley, W G, et al, Quarterly fournal of Medicine, 1974, 43, 145.

14 Pyke, D A, and Tattersall, R B, Diabetes, 1973, 22, 613.

15 Tattersall, R B, Quarterly fournal of Medicine, 1974, 43, 339.

${ }^{16}$ Becker, B, et al, Diabetes, 1977, 26, 997.

17 Cahill, G F, Etzwiler, D D, and Freinkel, N, New England fournal of Medicine, 1976, 294, 1004.

18 Ingelfinger, F J, New England fournal of Medicine, 1977, 296, 1228.

\section{Sulphinpyrazone, cardiac infarction, and the prevention of death: a successful trial or another tribulation?}

While the present century has seen the clinical and pathological recognition of myocardial infarction, only with the appearance of Samuel Levine's monograph ${ }^{1}$ did the diagnosis become acceptable during life. In 1929, however, treatment could be only masterly inactivity. Are we any better off now, once the acute phase has passed and the patient has left hospital ? Given that we know so little about how to prevent the disorder in the first place, ${ }^{2}$ what price secondary prevention? Bitter disappointments over the last three decades have forced us to look extremely carefully at any new means of reducing the incidence of cardiac deaths after myocardial infarction, even when, as in the recent American study on sulphinpyrazone (Anturan), ${ }^{3}$ there are sound theoretical reasons for expecting some benefit.

A review of the results of attempts to reduce the mortality rate makes disheartening reading. Initial enthusiasm for longterm oral anticoagulant treatment ${ }^{4}$ soon turned sour, and it has now fallen into disrepute. ${ }^{5}$ At least it achieved one important benefit: it made cardiologists realise the importance of the proper design of trials with sound statistical methods and avoidance of bias in selecting patients. Even so, it would be foolish to ignore the considerable evidence linking thrombosis with the progression of atheroma, ${ }^{6}$ because in some way this association might be harnessed for treatment. 
What of other methods of prevention? At one stage clofibrate seemed promising, but interpretation of the data proved difficult, ${ }^{7}$ and the drug has not stood the test of time. The difficulties inherent in multicentre trials became clear in the extensive investigation of practolol, ${ }^{8}$ when somewhat discrepant results emerged suggesting that the drug had differential effects, with greater benefit to patients with anterior rather than inferior infarction. It still remains to be seen whether this can be correlated with the sympathetic innervation of the ventricles. ${ }^{9}$ The trial could not be completed because practolol proved toxic, and we still await the results of other, larger, studies on other beta-adrenergic blockers. Enthusiastic shortterm claims for disopyramide ${ }^{10}$ seem unwarranted, ${ }^{11}$ but a better-designed trial of this substance might now have to be contemplated. ${ }^{12}$

So should we look again at antithrombotic agents? Has knowledge advanced sufficiently to suggest that these may prevent further infarcts or sudden death in those who have had an infarct? Such a thesis led Sherry et $a l^{3}$ to consider the potential value of sulphinpyrazone, a uricosuric agent used to treat gout, which had been found to lengthen platelet survival and decrease platelet turnover in various thromboembolic disorders. ${ }^{13}$ Sherry et al believed that sulphinpyrazone seemed a promising prospect for two reasons: firstly, its inhibition of platelet adhesion and aggregation in vivo and in vitro and of the "release reaction" induced by adenosine diphosphate, collagen, and antigen-antibody complexes; and, secondly, its inhibition of platelet prostaglandin synthesis. Other substances with similar actions include aspirin and dipyridamole, and there is some evidence that aspirin may be beneficial in protecting against cardiac death in survivors of myocardial infarction. ${ }^{14}$

In this trial patients aged $45-70$ were entered at least 25 days after the last myocardial infarction, and sulphinpyrazone (800 mg daily) was compared with placebo. From several North American centres 1475 patients (733 treated with sulphinpyrazone and 742 with placebo) were available for analysis. Compliance was good, and scrutiny of the patients careful. On the basis of an average of 8.4 months' observation, the annual cardiac death rate was $9.5 \%$ in the placebo group and $4.9 \%$ in the sulphinpyrazone group: this observed reduction of $48.5^{\circ}$ ow significant $(\mathbf{P}=0.018)$. The annual suddencardiac-death rate was $6.3 \%$ for the placebo group and $2.7 \%$ for those taking sulphinpyrazone, a similar reduction with similar significance.

These results might seem encouraging, and indeed the authors claim that "sulfinpyrazone appears to be effective in reducing cardiac death during the first year after myocardial infarction." Nevertheless, we must express some doubts-even though, as Sherry et al analysed the results, they decided that these were so convincing that they had an ethical obligation to disclose the findings to all the patients and to offer them a choice: to stay in the trial (without breaking the drug/placebo code) or to withdraw. In practically every respect matching was close with no important difference, save in one crucial respect -abnormality of heart rhythm. At the time of entry into the trial an arrhythmia was found in $11.3 \%$ in the sulphinpyrazone group and $15 \%$ in the placebo group, a difference significant at much the same level as the reduction in death rate. Unfortunately, we are not told what constituted "abnormality of rhythm," but we need detailed information before we can know if the results really mean what they might seem to. For example, if there were a preponderance of patients in the placebo group with ventricular arrhythmias, as distinct from isolated atrial extrasystoles, compared with the sulphin- pyrazone group it would explain much of the difference seen in the analysis. We are promised in the final report on the trial a detailed analysis of the electrocardiographic findings on all patients, but perhaps this is insufficient. Though serum enzyme concentrations were recorded during the period of infarction we are not told whether these were higher in one group or the other; future trials might well bear in mind the possible difference in the size of infarct as well as its location in deter- $\frac{\text { f }}{9}$ mining the prognosis of patients.

All these apparent cavils will make life more difficult for the $\frac{\overline{0}}{\overline{0}}$ investigator. Nevertheless, there have been so many trials $\frac{\mathbb{D}}{\nabla}$ whose defects have become apparent only after so much effort $\varrho$ has been expended that a hypercritical attitude is justified. Perhaps we need quantitative estimations of infarct size- $\overrightarrow{0}$ however approximate-by estimating serial creatine kinase $\overrightarrow{\vec{\omega}}$ concentrations $^{1.5}$ or precordial electrocardiographic mapping. ${ }^{16} \stackrel{\text { W }}{\text { W }}$ It would also be useful to know more about the state of the $\frac{5}{3}$ arteries in specific individuals if we are to investigate mechanisms aimed at inhibiting coagulation in or on their ss vessels. If the results of the trial are to mean anything, it will $\vec{\infty}$ obviously have to be repeated with due attention paid to the discrepancies that have been recognised-and perhaps by that $\overrightarrow{\dot{\theta}}$ time we will have more effective and specific inhibitors of platelet prostaglandins. Before succumbing to either therapeutic nihilism or enthusiasm we need to look even more closely at $\vec{F}$ how to design trials in patients who have had an infarct. In this way we may get acceptable answers, rather than raising both hopes and questions as each trial is completed.

${ }^{1}$ Levine, S A, Coronary Thrombosis: Its Various Clinical Features. London, Baillière, Tindall and Cox, 1929.

${ }^{2}$ Report of a Joint Working Party of the Royal College of Physicians of London and the British Cardiac Society, fournal of the Royal College of Physicians, 1976, 10, 214.

${ }^{3}$ Anturane Reinfarction Trial Research Group, New England fournal of Medicine, 1978, 298, 289.

${ }^{4}$ Suzman, M M, Ruskin, H D, and Goldberg, B, Circulation, 1955, 12, 338.

McMichael, J, and Parry, E H, Lancet, 1960, 2, 991.

${ }^{6}$ Woolf, N, et al, British fournal of Experimental Pathology, 1968, 49, 257.

${ }^{7}$ Dewar, H A, and Oliver, M F, British Medical fournal, 1971, 4, 784.

${ }^{8}$ Multicentre International Study, British Medical fournal, 1975, 3, 735.

${ }^{9}$ Randall, W C, ed, Neural Regulation of the Heart. New York, Oxford University Press, 1977.

10 Zainal, N, et al, Lancet, 1977, 2, 887.

11 Dollery, C T, Krikler, D M, and Shillingford, I P, Lancet, 1977, 2, 1185.

12 Julian, D G, Lancet, 1977, 2, 1362.

13 Smythe, H A, et al, Canadian Medical Association fournal, 1965, 92, 818.

${ }^{14}$ Elwood, P C, et al, British Medical fournal, 1974, 1, 436.

15 Bleifeld, W, et al, Circulation, 1977, 55, 303.

${ }^{16}$ Muller, J E, Maroko, P R, and Braunwald, E, Circulation, 1978, 57, 1.

\section{Non-A non-B hepatitis}

We now have highly sensitive techniques for diagnosing hepatitis A and B virus infections. As a result of using these another variant of acute hepatitis has been discovered, in which neither of these viruses nor their immunological markers can be detected. Called non-A non-B hepatitis, the agent or agents responsible have not yet been identified and the diagnosis is essentially one of exclusion, but already we know a lot about its epidemiology, clinical course, and long-term consequences.

Studies on post-transfusion cases $^{1-3}$ have shown that the mean incubation period is similar to that of hepatitis $B$, although it ranges from 18 to over 100 days. The clinical 